\title{
ESTRATÉGIA DE PLANEJAMENTO DO SORTIMENTO: UM ESTUDO DE CASO DO VAREJO DE ALIMENTOS NO BRASIL
}

\section{STRATEGY OF ASSORTMENT'S PLANNING: A CASE STUDY IN FOOD RETAIL IN BRAZIL}

\begin{abstract}
Claudimar Pereira Da Veiga ${ }^{1}$
Cássia Rita Pereira Da Veiga ${ }^{2}$

Kawana Harue Sato $^{3}$

Ubiratã Tortato $^{4}$

\section{Resumo}

Na cadeia de suprimentos é o varejo quem seleciona a ocupação dos depósitos e do espaço de prateleira. Entretanto, para sobreviver em um ambiente competitivo e estabelecer uma forte posição no mercado, os varejistas devem gerenciar de maneira eficaz suas atividades e fornecer um nível de serviço adequado ao consumidor. Neste contexto, o objetivo deste estudo é avaliar a estratégia de planejamento do sortimento com redução do mix. Trata-se de um estudo de caso no varejo de alimentos. Os resultados da nova estratégia demonstraram considerável aumento no volume de vendas e no share de mercado.
\end{abstract}

Palavras chave: Estratégia no Varejo, Planejamento do Sortimento, Redução de SKUs

\footnotetext{
${ }^{1}$ claudimar.veiga@gmail.com. Brasil, Mestre em Engenharia de Produção e Sistemas pela PUCPR (2009), Especialista em Finanças e Estratégias Empresariais Pela Universidade Federal de Uberlândia (2003) e MBA em Gestão Empresarial pela Escola de Negócios FAGEN UFU (2001). Rua Imaculada Conceição, 155. CEP: 80215-901. Curitiba - PR - Brasil.

2 cassia.veig@gmail.com. Brasil, Mestranda em Administração Estratégica - Programa de Pós - Graduação em Administração PPAD; MBA em Marketing pela Fundação Getúlio Vargas - FGV SP (2005). Avenida 9 de Julho, 2029. CEP: 01313-001. São Paulo - SP - Brasil.

3 kawana.sato@gmail.com. Brasil, Mestranda em Administração Estratégica - Programa de Pós -

Graduação em Administração PPAD. Rua Imaculada Conceição, 155. CEP: 80215-901. Curitiba - PR Brasil.

${ }^{4}$ ubirata.tortato@pucpr.br. Brasil, Doutor em Engenharia de Produção pela Universidade de São Paulo USP

(2006),

Mestre em Administração pela Universidade Federal do Paraná UFPR (1999). Professor Adjunto no Programa de Mestrado e Doutorado em Administração da PUCPR. Rua Imaculada Conceição, 155. CEP: 80215-901. Curitiba - PR - Brasil.
} 


\begin{abstract}
The retailer is who selects the occupation of deposits and shelf space in the supply chain. However, to survive in a competitive environment and to establish a strong market position, the retailers must manage their activities effectively and provide an adequate level of service to the consumer. In this context, the objective of this study is to evaluate the strategy to reduce the available assortment to the consumer. This is a case study in the food retail. The results showed that the strategy of assortment reduction resulted in considerable increase in sales volume and market share.
\end{abstract}

Keywords: Retail strategy, Assortment Planning, Reducing SKUs

\title{
Introdução
}

Os varejistas (supermercados, hipermercados, lojas de departamento, lojas de conveniência, etc.) ocupam uma posição privilegiada dentro do canal de distribuição, pois encontram-se mais próximos do consumidor. Por ocupar essa posição, o varejo dispõe de informações relativas ao comportamento, preferências e necessidades do consumidor. Quando bem administradas, tais informações podem representar uma significativa vantagem sobre os demais participantes da cadeia (BERTAGLIA, 2009).

$\mathrm{Na}$ medida em que o varejo teve possibilidades de obter tecnologias de informação que o capacitassem a adquirir informações sobre os consumidores e a desenvolver práticas logísticas para obter vantagens competitivas, verificou-se uma redefinição no equilíbrio do poder na cadeia de suprimentos. Acrescenta-se, ainda, a este contexto, o aumento na quantidade de novos produtos lançados no mercado, bem como o número de categorias de produtos disponíveis, que enfrentam a disponibilidade limitada de espaço nas prateleiras e recursos para estoque (ARKADER; FERREIRA, 2004; SANTOS; GIMENEZ, 1999; CADEAUX, 1997). Na cadeia de suprimentos é o varejo quem seleciona a ocupação dos depósitos e do espaço de prateleira através de uma negociação que envolve os dois lados da transação (WILKIE; DESROCHERS; GUNDLACH, 2002) 
Todos esses fatores criaram um cenário que favoreceu e despertou a necessidade de adaptação de varejistas, fornecedores e fabricantes a uma nova realidade em que a colaboração e as decisões integradas passaram a oferecer melhores resultados a todos os integrantes da cadeia. Como consequência, novas práticas de gerenciamento da cadeia de suprimentos foram incorporadas à indústria varejista, tais como ECR (Efficient Consumer Response ou Resposta Eficiente ao Consumidor) e iniciativas colaborativas na cadeia de suprimentos (ARKADER; FERREIRA, 2004). Holmström et al. (2002) destacam duas novas práticas que surgiram por volta dos anos 90 , em função dessa nova realidade: o gerenciamento de categorias para o varejo e o reabastecimento para o fornecedor.

O gerenciamento de categorias possibilita que a organização utilize informações sobre o consumidor para definir aspectos chave para o negócio. Dentre as práticas de gerenciamento de categorias, o planejamento do sortimento está entre as mais adotadas, pois permite, por exemplo, a eliminação de artigos pouco lucrativos e que ocupam o espaço físico que poderia ser destinado à exposição de outros produtos. Além disso, para atender ao mercado, os canais de distribuição devem oferecer aos consumidores e usuários finais os níveis desejados de variedade e sortimento de produtos (BOWERSOX; CLOSS; COOPER, 2006). Do ponto de vista do consumidor, a preferência é por sortimentos amplos devido as suas necessidades por maiores opções de escolha e também pela atratividade do sortimento (BOYD; BAHN, 2009). Entretanto, os custos associados à disposição de grandes sortimentos são elevados, e cada vez mais os varejistas estão conscientes de tais custos (OPPEWAL; KOELEMEIJER, 2005).

Diante disso, as decisões sobre o planejamento do sortimento tornam-se um aspecto estratégico essencial, uma vez que tanto varejistas, como fabricantes e fornecedores devem oferecer aos clientes um equilíbrio entre variedade, profundidade e nível de serviço. Desse modo, o planejamento do sortimento deve levar em consideração aspectos que vão além das percepções e respostas dos consumidores ao sortimento, tais como as limitações do espaço físico no varejo, os investimentos em estoques, flutuações na demanda, fatores ambientais, entre outros. 
Neste contexto, propõe-se como objetivo deste estudo investigar uma estratégia do planejamento do sortimento sob o ponto de vista da cadeia de suprimentos, em especial, verificar as conseqüências da implementação de uma estratégia de redução de sortimento de produtos. Pretende-se, com este estudo, contribuir no sentido de prover um melhor entendimento dos problemas associados à tomada de decisão dos sortimentos, bem como levantar as possíveis influências de tais decisões aos membros da cadeia.

Para tanto, este trabalho encontra-se dividido em seis seções sendo a introdução a primeira seção. Na seção seguinte apresenta-se o referencial teórico-empírico, incluindo subseções que expõe os conceitos do gerenciamento da cadeia de suprimentos, assim como do planejamento do sortimento. Na terceira seção apresenta-se as decisões sobre o sortimento na cadeia de suprimentos. Na quarta seção os procedimentos metodológicos são abordados. A seção cinco destina-se à apresentação e análise dos resultados. Por fím, apresenta-se a conclusão e sugestões para futuras pesquisas.

\section{Gerenciamento da cadeia de suprimentos}

Uma das mudanças mais significantes ocorridas na gestão de negócios foi a transição da competição entre organizações individuais para a competição entre cadeias de suprimentos. Neste ambiente competitivo, o sucesso organizacional passou a depender da habilidade das organizações no gerenciamento dos relacionamentos entre os parceiros da cadeia e da coordenação de atividades e processos dentro da cadeia de abastecimento (LAMBERT; COOPER, 2000). Nesse sentido, algumas inovações na cadeia de suprimentos ocorreram por volta dos anos 1990. Duas mudanças são destacadas por Holmström et al. (2002): o reabastecimento e o gerenciamento de categorias (GC).

O reabastecimento, uma inovação no fornecimento de produtos, modificou a maneira pela qual os produtos são entregues ao varejo. Por meio do reabastecimento o fornecedor passa a realizar suas entregas de acordo com o consumo dos produtos. Sendo assim, a entrega não dependerá mais de pedidos realizados pelo varejo. Esta mudança deu-se em parte pela percepção de que a maneira mais fácil de melhorar a eficiência 
operacional era mudar as práticas varejistas. Essa mudança poderá resultar em diminuições de custos significantes, entretanto deve estar associada ao gerenciamento eficiente de informações, principalmente na diminuição de atrasos de repasse de informações relacionadas à demanda, além de uma consolidação do fluxo de materiais (HOLMSTRÖM et al., 2002).

Por sua vez, o GC foi uma inovação que alterou principalmente as práticas do varejo. Segundo Holmström et al.. (2002) “o GC é basicamente uma revisão periódica e um processo de decisão do sortimento executado no nível da loja”. De acordo com os autores, o GC permitiu aos varejistas gerenciar os produtos oferecidos aos consumidores de maneira sistemática, com o objetivo de minimizar os problemas associados ao espaço físico no varejo ao mesmo tempo em que oferece valor ao cliente. Numa visão prática, o GC significou que o processo de decisão sobre o sortimento não seria mais influenciado pelas promoções vindas do fornecedor e nem pelo lançamento de novos produtos.

De acordo com os resultados do estudo realizado por Arkader e Ferreira (2004), dentre as práticas de GC, as táticas mais intensamente adotadas nas operações de varejo foram o sortimento e a exposição. Segundo os autores, no caso do sortimento, pode-se afirmar que a sua utilização parece estar associada à possibilidade de eliminação de artigos menos lucrativos e com baixa rotatividade, disponibilizando mais espaço na prateleira para produtos que efetivamente contribuem para a lucratividade da empresa. Por isso, considera-se que o sortimento é uma estratégia que introduz melhorias nas decisões de compra no varejo.

No caso da exposição, pode-se considerar que o uso desta tática possibilita a avaliação de melhores posicionamentos da categoria do produto no espaço da loja, seja no nível macro do espaço da loja (por meio da observação do fluxo de clientes e das necessidades de exposição da categoria) ou no nível micro do espaço (correspondente à prateleira).

\section{Planejamento do sortimento}

Revista Administração em Diálogo ISSN 2178-0080 
Para obter resultados satisfatórios nos processo de tomada de decisão, o varejista deve considera três níveis de análise (YUCEL et al., 2009). No nível tático, o varejista deve escolher quais produtos oferecer para seus clientes e com quais fornecedores trabalhar. No nível operacional, dada a variedade de produtos e os fornecedores, o varejista deve escolher quanto pedir de cada produto considerando a reação dos consumidores para o sortimento, o inventário disponível e a limitação no espaço de prateleira. No nível estratégico, o planejamento do sortimento representa um dos principais elementos, pois permite à organização eliminar os artigos pouco lucrativos e focar em produtos que realmente trazem os retornos esperados.

Desta forma, uma das decisões básicas do varejista está relacionada ao sortimento de produtos a serem oferecidos aos seus clientes (MANTRALA et al., 2009). É por meio da disponibilização de produtos no tempo, lugar e quantidades certas que o varejista consegue adicionar valor aos seus produtos (OPPEWAL; KOELEMEIJER, 2005).

O sortimento no varejo é definido como o conjunto de produtos disponibilizados ao cliente em uma loja em um ponto no tempo e tem por objetivo maximizar as vendas ou os lucros, mas está sujeito a diversas limitações (KÖK; FISHER; VAIDYANATHAN, 2006). Rajaram (2001) acrescenta que o planejamento do sortimento está relacionado ao processo de decisão sobre quantos e quais produtos farão parte de uma determinada linha de produto, além de determinar o nível de estoque para tais produtos. Portanto, o gerenciamento do sortimento torna-se crucial uma vez que o seu mau planejamento pode levar a gastos elevados com estoques em excesso e de produtos sem demanda, levando a perdas de oportunidades de vendas.

O sortimento dos produtos deve ser planejado de modo a oferecer um equilíbrio entre variedade (categorias de produtos ou largura), profundidade (número de SKUs stock-keeping units - dentro da categoria) e nível de serviço (quantidade dos itens individuais). Como apontado por Mantrala et al. (2009), a oferta de maior variedade implicará numa redução da profundidade na categoria ou redução do nível de serviço, ou ainda, na redução de ambos. Desse modo, o planejamento do sortimento está vinculado a 
uma série de trade-offs, no qual a decisão entre profundidade e largura torna-se uma decisão estratégica, pois poderá influenciar na imagem da loja perante os consumidores (BRONIARCZYK; HOYER; McALISTER, 1998; KÖK; FISHER; VAIDYANATHAN, 2006).

Para Mantrala et al. (2009), o sortimento deve ser planejado levando-se em consideração uma série de aspectos. Três podem ser considerados principais. $\mathrm{O}$ primeiro aspecto refere-se às limitações enfrentadas pelo varejo. A limitação mais aparente é o espaço físico disponível para a exposição de produtos. Como o espaço na prateleira é limitado, os itens selecionados para compor o sortimento deverão ser alocados naquele determinado espaço. Decisões para maiores sortimentos acarretarão numa menor exposição de cada item (menores faces expostas), diminuição do nível de serviço (estoque de cada item) e aumento no risco de falta de estoque (CAMPO; GIJSBRECHTS, 2005).

Considerando-se as limitações do varejo, Mantrala et al. (2009) destacam cinco fatores na tomada de decisão sobre a profundidade e nível de serviço de um sortimento:

i. A dimensão física do item influi no espaço que deverá ser destinado a ele.

ii. Quanto maior o espaço de prateleira alocado a um determinado item, maior a probabilidade de atrair consumidores a efetivar sua compra, o que leva à decisão de alocar espaço intencional e proporcionalmente às vendas.

iii. A demanda média e variabilidade de demanda influem no espaço necessário na prateleira. Assim, para atender a aumentos de demanda, os varejistas recorrem aos estoques na prateleira, a fim de evitar perdas pela falta de estoque. Nestes casos, é possível suavizar tais estoques em prateleiras por meio de parcerias entre varejistas e fornecedores, pela redução na quantidade de itens por pedido e o tempo de entrega (lead time). "Por exemplo, se o varejista pedir menos unidades de um SKU mais frequentemente, ele pode alocar menos espaço para este SKU sem correr o risco de falta de estoque" (p. 75). 
iv. Para determinar a quantidade de itens de um SKU, o varejista deve levar em consideração o nível de serviço que se deseja oferecer aos clientes, além de fazer escolhas estratégicas sobre quais itens terão alto nível de serviço e quais terão baixo nível de serviço.

v. O varejo deve considerar o ciclo de entrega dos produtos e o tamanho da embalagem na alocação de espaço físico. Embora alguns varejistas têm o poder de comprar quantidades somente necessárias, alguns são limitados à compra por lotes ou pacotes. Em função disto, e também do ciclo de entrega, por vezes o varejista deverá estocar mais produtos na prateleira do que o necessário.

Os fatores ambientais são o segundo aspecto destacado no planejamento do sortimento. Os fatores macroeconômicos e tendências ambientais devem ser considerados na decisão sobre variedade e profundidade do sortimento. A consideração de fatores ambientais e fatores específicos dos clientes na composição do sortimento permitem ao varejo oferecer produtos que satisfaçam as suas necessidades. Assim, customizar o sortimento de acordo com os fatores ambientais contribui para a formação de uma estratégia de sortimento mais competitiva (GREWAL et al., 1999; MANTRALA et al., 2009).

E por fim, mas não menos importante, as percepções e preferências do consumidor não podem ser desconsideradas no planejamento do sortimento já que todos os esforços se concentram para a satisfação dos mesmos. Além disso, a reação do consumidor ao sortimento é determinante na rentabilidade e nas vendas dos produtos (CAMPO; GIJSBRECHTS, 2005).

De maneira simplificada e do ponto de vista do consumidor, um sortimento ótimo deve incluir todos aqueles produtos que representam a primeira escolha dos consumidores do mercado-alvo. Porém a heterogeneidade das preferências e a exigência por mais opções e flexibilidade impossibilita soluções simples (MANTRALA et al., 2009). 
A disposição do consumidor em substituir um produto que está em falta por outro similar torna a decisão sobre o sortimento de produtos ainda mais complexa (AGRAWAL; SMITH, 2003), pois é um importante parâmetro no planejamento (KÖK; FISHER; VAIDYANATHAN, 2006). Se o consumidor é propenso à substituição do produto, então grandes investimentos em estoques podem ser desnecessários (MANTRALA et al., 2009), assim como a oferta de sortimentos com maior profundidade.

Entretanto, a disposição em substituir produtos em falta por similares pode ser gerenciada pelos varejistas, tornando-se uma ferramenta para administração e diminuição de perdas pela falta de estoques. Desse modo, a composição de categorias de produtos poderia ser realizada de modo que produtos substitutos fiquem disponíveis para aqueles itens "chave" que geralmente estão em falta (CAMPO; GIJSBRECHTS, 2005).

Diante de todos esses fatores e com o objetivo de atender às preferências e necessidades dos seus clientes, muitos assumem a posição de que sortimentos maiores oferecem maiores benefícios aos seus clientes do que sortimentos reduzidos. Entretanto, custos associados à disposição de grandes sortimentos são elevados, e cada vez mais os varejistas estão conscientes de tais custos (OPPEWAL; KOELEMEIJER, 2005).

Nesse sentido, pesquisas como as de Boatwright e Nunes (2001), Broniarczyk, Hoyer e McAlister (1998) e Iyengar e Lepper (2000) sugerem que é possível reduzir o número de SKUs oferecidos pelos varejistas sem comprometer as vendas. Em alguns casos, a remoção de itens no sortimento pode até aumentar as vendas.

Iyengar e Lepper (2000) argumentam que a complexidade associada aos sortimentos amplos que oferecem muitas alternativas pode ser fator desmotivador e demonstrar que mais opções não representam, na totalidade, altos níveis de vendas, podendo até influenciar de modo negativo na satisfação do consumidor. Sortimentos reduzidos parecem ser igualmente, ou até mais atrativos do que sortimentos que contém a alternativa preferida pelo consumidor. 
Broniarczyk, Hoyer e McAlister (1998) descobriram que para compras repetitivas de produtos em que o envolvimento do cliente é baixo, a redução do sortimento em $25 \%$ pode não ser percebida se a marca preferida continua disponível. De acordo com os autores, o item de preferência pode ser mais facilmente encontrado quando o sortimento é menor. Os pesquisadores sugerem ainda que o percentual de redução do sortimento pode ser aumentado em até $50 \%$ se o espaço na prateleira for mantido constante.

O planejamento do sortimento é bastante explorado na literatura sob o ponto de vista do varejo. Isto ocorre, possivelmente, porque a exposição dos produtos e o momento de decisão de compra do consumidor final ocorrem justamente no ambiente do varejo. Apesar disso, acredita-se que os problemas associados ao varejo, bem como as suas limitações também devem ser levados em consideração pelos fabricantes e fornecedores. Isto porque estes são os principais responsáveis pela produção e lançamento de novos produtos, assim como tem grande interesse nas vendas e satisfação dos clientes. Trata-se de um ambiente complexo para negociação com necessidade de colaboração mútua entre todos os elos da cadeia.

Em suma, pode-se dizer que com as crescentes limitações do varejo e com a importância do planejamento do sortimento, uma resposta eficiente às necessidades do consumidor depende de estratégias conjuntas entre os integrantes da cadeia. Devido a essa interdependência, as decisões tomadas sobre o sortimento podem influenciar em diversos, senão todos, os integrantes da cadeia de suprimentos. Tais implicações são apresentadas na próxima seção.

\section{As decisões sobre o sortimento na cadeia de suprimentos}

Divergências entre as linhas de produtos oferecidas pelo fabricante e o sortimento de produtos selecionados e estocados pelo varejo são muitas vezes encontradas (CADEAUX; 1997), principalmente quando a cadeia não está estruturada de maneira integrada. Tais divergências ocorrem porque o desejo do fabricante, na maioria das vezes, é de maximizar a disponibilidade de toda a sua linha de produtos no varejo (CADEAUX,

Revista Administração em Diálogo ISSN 2178-0080 
1997). O varejista, por outro lado, opta pela disponibilização de sortimentos menores àquele oferecido pelo fornecedor (KÖK; FISHER; VAIDYANATHAN, 2006).

Nestes casos, o planejamento do sortimento pelo varejista pode ser influenciado pelo fabricante, por meio do pagamento de taxas, denominadas slotting fees (KÖK; FISHER; VAIDYANATHAN, 2006). Essas taxas, segundo Wilkie, Desrochers e Gundlach (2002) são pagamentos efetuados pelos produtores para terem seus produtos estocados ou exibidos, podendo ser pagos em dinheiro ou na forma de subsídios, como bonificações de produtos ou descontos no pedido.

Um dos motivos pela qual os slotting fees são praticados está na transferência do poder do fabricante ao varejista. O aumento de lançamento de novos produtos, a disponibilidade limitada de espaço nas prateleiras e os altos investimentos necessários para estocar produtos implicam na adoção de estratégias para selecionar os estoques e o espaço de exposição do produto. Além disso, o aumento do grau de controle do fluxo de informações por parte do varejo com relação às vendas também podem justificar tais práticas (CADEAUX, 1997; WILKIE; DESROCHERS; GUNDLACH, 2002).

Em determinados casos, disponibilizar toda a variedade de produtos possíveis pode não ser a estratégia mais viável para o produtor. Apesar de haver uma possibilidade de maximização de vendas e lucros pela satisfação do desejo do consumidor de encontrar mais opções de escolha, a decisão do varejo de ofertar um sortimento amplo e variado aos consumidores é, sob a perspectiva das operações e da cadeia de suprimentos como um todo, uma decisão muito onerosa. Maior sortimento na prateleira implica em demandas menores e estoques menores de cada produto, baixa disponibilidade do produto, bem como em altos custos de manuseio (KÖK; FISHER; VAIDYANATHAN, 2006). Além disso, a diminuição no nível de serviço ao cliente acarreta em maiores riscos de falta de estoque.

As decisões relacionadas ao sortimento também geram implicações nos custos de produção. Um sortimento composto por uma grande variedade de SKUs pode limitar os 
ganhos obtidos através da economia de escala. Outro fator que deve ser considerado é a necessidade de paralisação do maquinário industrial em decorrência da mudança de item/sabor produzido. Nesta situação, quanto maior a composição do sortimento da empresa, maior tempo será gasto com este período de transição.

A tendência atual do varejo de comercializar suas próprias marcas interfere significativamente no planejamento do sortimento. As marcas próprias possuem custos inferiores, além da garantia de melhores margens e menores riscos (BERTAGLIA, 2009). Uma decisão do varejo de compor seu sortimento por marcas próprias pode influenciar no sortimento por dois caminhos: redução do espaço físico de exposição e menores investimentos em estoques dos demais produtos.

As decisões do varejo sobre o sortimento provocarão efeitos positivos ao longo da cadeia quando o varejo estiver compartilhando relacionamentos de parceria entre os membros da cadeia de suprimentos. Para o varejo, os benefícios de tal parceria refletem na redução de investimentos em estoques, que se torna possível pela adoção de práticas de reabastecimento em parceria com seus fornecedores.

No entanto, para que o abastecimento seja eficiente, informações sobre a demanda prevista devem ser repassadas aos membros da cadeia. Quanto mais os produtores aprendem sobre as preferências dos consumidores, mais aptos eles estarão a prever de maneira precisa a demanda do mercado. Entretanto, por estar posicionado próximo ao consumidor na cadeia, na maioria das vezes. somente o varejo possui domínio sobre as informações relativas ao comportamento do consumidor, suas preferências e necessidades (BERTAGLIA, 2009). Apesar disso, questões como custo de transação, problemas de comunicação e conflito entre os membros do canal desencorajam os varejistas a compartilharem suas informações com os fornecedores (CAO; JIANG; ZHOU, 2010).

Uma infraestrutura adequada para troca de informação é capaz de tornar disponíveis informações de demanda por toda a cadeia de suprimentos, muitas vezes em tempo perto do real. A infraestrutura adequada contribui para a redução do efeito chicote, 
além de desenvolver a colaboração entre os elos da cadeia (McLAREN; HEAD; YUAN, 2002). Esta colaboração é caracterizada pelas relações de troca e ações integradas muitas vezes motivadas pelo alcance de vantagem estratégica em complemento aos motivos econômicos (KIM, 1999).

A troca de informações e um maior conhecimento sobre demanda final permitem aos membros da cadeia uma redução dos seus estoques, já que os estoques dos parceiros da cadeia estão relacionados (CAMPOS; STAMFORD; CAMPOS, 2002). Adicionalmente, é possível realizar um planejamento eficiente de produção com o conhecimento da demanda real, evitando assim desperdícios e perdas, principalmente para os fornecedores de produtos perecíveis ou com ciclo de vida reduzido.

Segundo Holmström et al. (2002), experimentos comprovam os resultados positivos da adoção de práticas colaborativas relacionadas à troca de informações de demanda e reabastecimento. O varejo pode obter maior volume de vendas, maior rentabilidade e redução no tempo de fornecimento. Para o fornecedor, o principal benefício é a diminuição dos riscos de substituição dos seus produtos por similares concorrentes (MANTRALA et al., 2009). O reabastecimento permite ao fornecedor administrar as faltas de estoque, evitando assim que a falta do produto na prateleira represente perda de vendas.

\section{Procedimentos metodológicos - delineamento de pesquisa e coleta de dados}

O presente trabalho se caracteriza como uma investigação descritiva ex-post-fact. $\mathrm{Na}$ forma de estudo de caso, buscou analisar um fato real para alcançar um conhecimento detalhado da situação (YIN, 1987). Para isso, foram utilizados dados qualitativos e quantitativos históricos, observação direta e entrevistas sistemáticas, combinando diferentes métodos para permitir a triangulação (VOSS; TSIKRIKTSIS; FROHLICH, 2002). seu mercado de atuação, como pelo acesso dos pesquisadores. O período de análise 
selecionado foi baseado na ocorrência do fenômeno em estudo. A redução de SKUs no mix de produtos alimentícios lácteos light no mercado da região analisada para todo o varejo ocorreu em janeiro de 2009. A análise abrangeu o período temporal anterior e posterior à redução do sortimento em uma investigação longitudinal com corte transversal.

Dados primários foram coletados por meio de entrevista com o gestor responsável pela área geográfica avaliada. Para a realização da entrevista, foi desenvolvido um roteiro com base na literatura, de modo que fosse incorporado um conjunto de atributos relacionados à variedade de produtos, as estratégias desenvolvidas pela empresa, detalhamento de rotinas organizacionais, participação de mercado, inovação, foco em custos e desempenho, parcerias, formação de redes e concorrência. Por se tratar de um roteiro, à medida que a entrevista se realizava, o roteiro era adaptado para atender às especificidades da empresa estudada.

Dados secundários também foram coletados, sendo fornecidos diretamente pela empresa. Estes abrangiam o volume de vendas correspondente aos períodos anteriores e posteriores à implementação da estratégia de redução de SKUs.

\section{Apresentação e análise de resultados - Perfil da empresa pesquisada}

O estudo de caso foi realizado em uma empresa de alimentos no Brasil por meio da análise histórica de dados de vendas no período de 2008 a 2009. A indústria em estudo é uma empresa de grande representatividade no mercado brasileiro e figura entre as oito líderes do segmento em que atua. Ela é composta por unidades industriais e unidades de negócios concentradas nas principais regiões do país. Seu portfólio é composto por produtos de linha seca, lácteos e congelados com grande diversificação de mix dentro de cada divisão.

Neste estudo de caso foram utilizados dados históricos de vendas de uma unidade de negócio no período entre 2008 e 2009 para os grupos de produtos alimentícios lácteos light. Essa linha de produtos apresentava em 2008 um sortimento composto por 12 SKUs.

Revista Administração em Diálogo ISSN 2178-0080 
A estratégia de redução do mix ocorreu em 2009 com alteração do sortimento para 7 SKUs. A estratégia foi implementada no primeiro trimestre de 2009 com o objetivo de melhorar a posição da empresa na participação de mercado em volume de vendas. Para tanto, foram retirados do mercado os produtos que apresentavam baixa rotatividade e altos índices de indenizações por trocas. É importante ressaltar que, no período de análise, a empresa não realizou ações promocionais com o objetivo de alterar o volume de vendas ou para obter maior espaço de prateleira ou exposição no ponto de venda. Os resultados apresentados nesta seção foram alcançados em função da estratégia de redução do sortimento.

A categoria de alimentos light foi selecionada pela empresa para a implementação da estratégia por se tratar de um segmento promissor e por ser foco da indústria em análise. Esta categoria apresenta uma rentabilidade superior às demais e atinge um público formador de opinião, com foco na árvore de decisão de compra na categoria de bem estar. Dentro do mercado total de alimentos lácteos, a categoria light assume cada vez mais importância devido à crescente preocupação dos consumidores em utilizar produtos com baixa caloria e teor de açúcar. Esta categoria representa aproximadamente $17 \%$ do mercado total dos laticínios.

\section{Análise e discussão dos dados}

A redução do sortimento foi analisada no âmbito da produção industrial e do espaço físico do ponto de venda (PDV) através dos dados qualitativos. Com a redução do sortimento, houve uma redução na variedade de produtos a serem produzidos, o que permitiu disponibilizar as máquinas para produção de outras linhas. Menor sortimento também significou a diminuição do número de fornecedores e investimentos mais direcionados. Para a equipe comercial, por sua vez, foi possível focar em produtos estratégicos. Da mesma forma, para os promotores e os repositores houve ganho no tempo para exposição e abastecimento dos itens. 
Com relação à disponibilidade de espaço no PDV, a redução do sortimento trouxe benefícios ainda maiores. Os balcões, prateleiras, freezers, gôndolas e ponto extra para exposição não aumentam na proporção dos lançamentos de novos produtos. Na linguagem do varejo, os balcões não são "elásticos" para suportar tantos lançamentos. Desta forma, com menores quantidades de SKUs a empresa pôde expor melhor seus produtos no mesmo espaço utilizado em 2008. A empresa focou nos produtos com maior giro e nos sabores aprovados por grande parte dos consumidores da marca. Os resultados quantitativos descritos a seguir confirmam as avaliações qualitativas e as considerações de Broniarczyk, Hoyer e McAlister (1998), que afirmam ser possível reduzir o sortimento sem o comprometimento das vendas, desde que o produto de preferência do cliente seja mantido.

Antes de descrever os resultados quantitativos em volume de vendas, é importante avaliar a situação do mercado brasileiro e do mercado na região estudada para os produtos light nos anos de 2008 e 2009. Esta análise se faz necessária para verificar a possível interferencia de fatores externos nos resultados alcançados pela organização estudada. A análise envolveu dados de pesquisa AC Nielsen (2010). A Tabela 1 e a Figura 1 demonstram que o mercado total de lácteos light no Brasil movimentou um volume de vendas de 48.683,10 toneladas no ano de 2008 e 55.031,40 toneladas em 2009 , um crescimento de $13,16 \%$. O mercado total de lácteos light na região foco da pesquisa apresentou um volume de vendas de 13.058 toneladas em 2008 e 14.102,30 toneladas em 2009, o que representa um crescimento de 8,0\%. Na empresa, após implementação da estratégia de redução de 12 SKUs para 7 SKUs, as vendas cresceram $20,39 \%$, valor muito superior àquele apresentado para a região analisada e para o Brasil. De uma forma geral, pode-se dizer que o crescimento do volume de vendas da empresa é decorrente da estratégia de redução de mix, não do crescimento natural do mercado. Com relação ao share de volume, a empresa apresentou crescimento de $0,4 \%$, sendo 3,2 em 2008 e $3,6 \%$ em 2009.

Tabela 1: Volume de vendas em toneladas no período entre 2008 e 2009

Revista Administração em Diálogo ISSN 2178-0080 
Claudimar Pereira da Veiga, Cássia Rita Pereira da Veiga, Kawana Harue Sato, Ubiratã Tortaro. RAD Vol.13, n.1, Jan/Fev/Mar/Abr 2011, p.01-24.

\begin{tabular}{|c|c|c|c|}
\hline PERÍODO & TOTAL BRASIL & $\begin{array}{c}\text { TOTAL REGIÃO } \\
\text { ANALISADA }\end{array}$ & $\begin{array}{c}\text { TOTAL } \\
\text { EMPRESA } \\
\text { REGIÃO } \\
\text { ANALISADA }\end{array}$ \\
\hline $\mathrm{jan} / 08$ & $3.023,02$ & $1.169,60$ & 39,30 \\
\hline fev/08 & $3.913,20$ & $1.054,50$ & 39,10 \\
\hline $\mathrm{mar} / 08$ & $4.111,80$ & $1.155,00$ & 39,60 \\
\hline $\mathrm{abr} / 08$ & $4.131,90$ & $1.128,20$ & 35,80 \\
\hline mai/08 & $4.005,00$ & $1.041,30$ & 33,20 \\
\hline jun/08 & $3.919,90$ & 968,90 & 29,60 \\
\hline jul/08 & $3.708,20$ & 890,80 & 30,60 \\
\hline ago/08 & $3.858,70$ & 980,50 & 31,50 \\
\hline set/08 & $4.251,20$ & $1.073,80$ & 38,20 \\
\hline out/08 & $4.430,30$ & $1.161,00$ & 31,10 \\
\hline nov/08 & $4.691,00$ & $1.210,40$ & 34,70 \\
\hline $\mathrm{dez} / 08$ & $4.586,90$ & $1.224,00$ & 36,60 \\
\hline jan/09 & $4.281,10$ & $1.169,60$ & 32,10 \\
\hline $\mathrm{fev} / 09$ & $4.767,20$ & $1.267,50$ & 37,70 \\
\hline $\mathrm{mar} / 09$ & $4.974,40$ & $1.372,20$ & 44,30 \\
\hline abr/09 & $4.828,50$ & $1.339,40$ & 40,50 \\
\hline mai/09 & $4.526,10$ & $1.194,60$ & 42,40 \\
\hline jun/09 & $4.270,70$ & $1.044,50$ & 38,30 \\
\hline $\mathrm{jul} / 09$ & $4.046,10$ & 957,20 & 35,70 \\
\hline ago/09 & $4.276,30$ & 968,90 & 38,40 \\
\hline set/09 & $4.625,60$ & $1.117,70$ & 43,10 \\
\hline out/09 & $4.738,90$ & $1.158,40$ & 41,90 \\
\hline nov/09 & $4.912,60$ & $1.235,20$ & 50,30 \\
\hline $\mathrm{dez} / 09$ & $4.783,90$ & $1.277,10$ & 60,10 \\
\hline Total 2008 & 48.631,12 & 13.058,00 & 419,30 \\
\hline Total 2009 & $55.031,40$ & $14.102,30$ & 504,80 \\
\hline Crescimento \% & 13,16 & 8,00 & 20,39 \\
\hline
\end{tabular}

Fonte: Adaptado de AC NIELSEN (2010) 


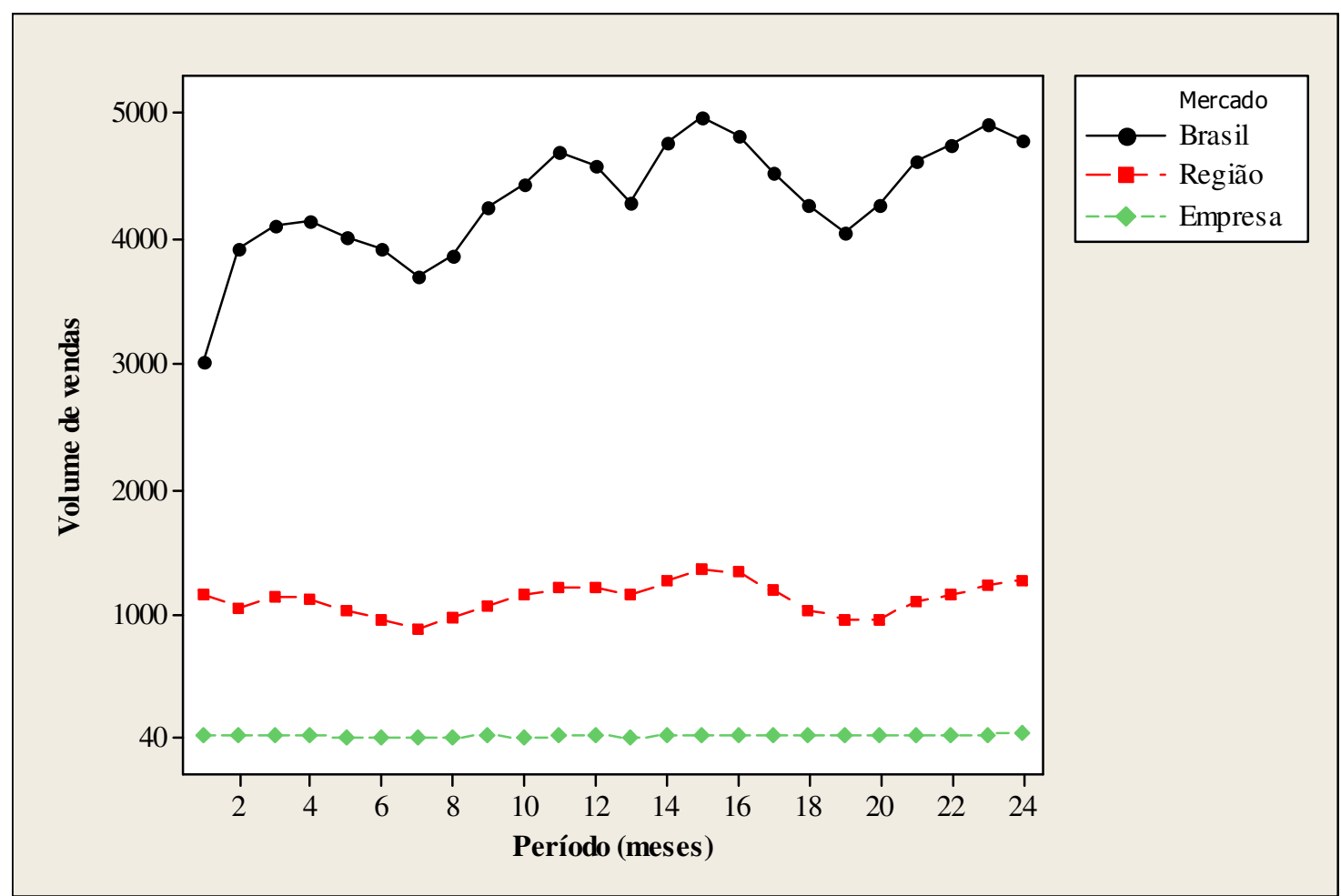

Figura 1: Participação de mercado em volume de vendas

Fonte: Adaptado de AC NIELSEN (2010)

A Figura 2 apresenta dados de volume de vendas da empresa no perídodo de 2008 e 2009. A série temporal de 2009 apresentou comportamento muito semelhante aos dados de 2008, com padrões equivalentes para tendência e sazonalidade. Este fato comprova que o volume de vendas da empresa em 2009 foi alterado em função da estratégia de redução de sortimento uma vez que o comportamento padrão do mercado é mantido nos dois perídos de análise. Nota-se que a partir do mês 2 , os resultados de volume de vendas para 2009 se mostraram significativamente superiores àqueles alcançados em 2008. Em 2008, quando a empresa em análise ainda operava com 12 SKUs, o volume de vendas para todo o ano foi de 419,30 toneladas. Já em 2009, a empresa obteve 504,80 toneladas em volume de vendas, o que significa um aumento no volume total de vendas de 20,39\% comparado ao mesmo período de 2008.

O presente trabalho descreveu a redução de sortimento de produtos alimentícios lácteos light disponibilizados ao consumidor e os benefícios decorrentes desta mudança 
estratégica. Os resultados demonstraram que decisões sobre o planejamento do sortimento assumem um papel primordial na estratégia da cadeia de suprimentos como um todo, uma vez que tanto varejistas, como fabricantes e fornecedores devem oferecer aos clientes um equilíbrio entre variedade, profundidade e nível de serviço. Diante disso, tomadas de decisão sobre sortimento tem emergido como uma importante arma competitiva para influenciar a venda de produtos no varejo.

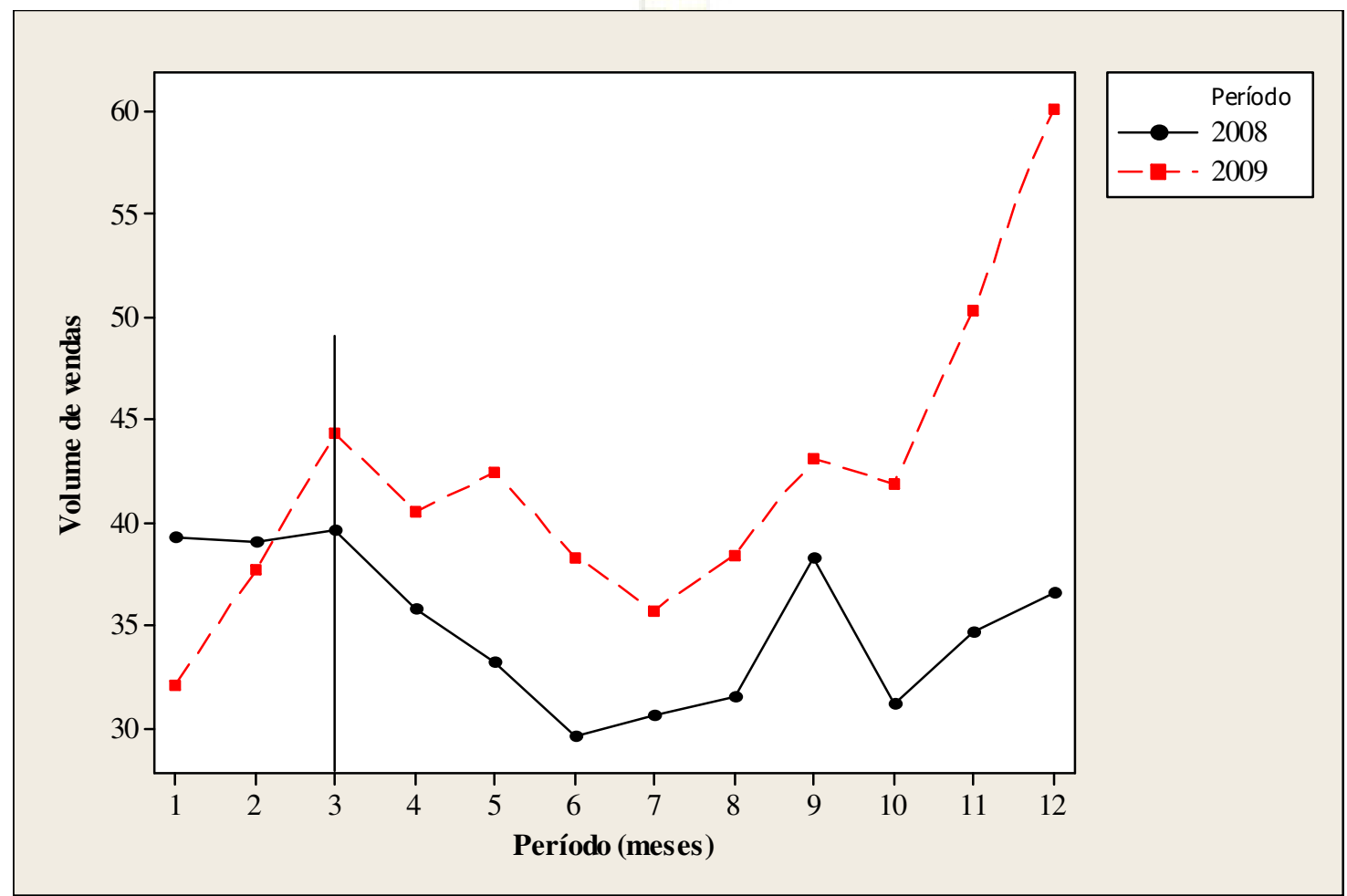

Figura 2 - Comparação do volume de vendas em 2008 e 2009

Fonte: Dados de pesquisa

\section{Considerações Finais}

Algumas alterações ocorridas no âmbito econômico e político no Brasil, nas últimas décadas, obrigaram as empresas a explorarem soluções geradoras de renda, essenciais para a manutenção do próprio negócio. Como conseqüência, as empresas passaram por diversas adequações a fim de aumentar a eficiência do processo produtivo e a qualidade dos produtos ofertados (BLAYNEY; GEHLHAR, 2005). 
A decisão do varejo por um sortimento reduzido pode implicar em perdas para o produtor em função da divergência entre a oferta de produtos e a decisão de sortimento pelo varejista. Além disso, a redução do sortimento pode acarretar diminuição de demanda para cada item e elevação dos custos associados ao manuseio para o fornecedor. Decisões isoladas do varejo podem trazer conseqüências negativas para os elos anteriores da cadeia de suprimentos

Por outro lado, efeitos positivos serão sentidos por todos os membros da cadeia quando as decisões do varejo relativas ao sortimento estiverem pautadas no desenvolvimento de parcerias entre os membros da cadeia. Para o varejo, pode-se citar como benefícios a redução dos estoques, redução do tempo de abastecimento, aumento das vendas e da rentabilidade. Para o fabricante é possível apontar a diminuição dos estoques como resultados, maior acesso às informações relativas ao consumidor, melhoria no nível de serviço e melhores resultados financeiros devido ao aumento das vendas.

O estudo de caso realizado em uma empresa da indústria alimentícia, especialmente na categoria de produtos alimentícios lácteos light, corrobora as evidências empíricas encontradas na literatura a respeito do planejamento do sortimento. Esta pesquisa confirma os resultados dos estudos de Boatwright e Nunes (2001), Broniarczyk, Hoyer e McAlister (1998) e Iyengar e Lepper (2000) que sugerem que é possível reduzir o número de SKUs oferecidos no varejo sem comprometer as vendas. No caso estudado, a remoção de itens no sortimento representou um aumento nas vendas, o que pode ser explicado pela confusão que os grandes sortimentos podem gerar nos clientes, tornando sortimentos reduzidos muitas vezes mais atrativos (OPPEWAL; KOELEMEIJER, 2005).

Para finalizar, é importante destacar que pesquisas científicas com recortes limitados representam uma abstração da realidade. Assim, a tomada de decisão pelo sortimento ideal é apenas uma pequena parte da negociação que ocorre entre varejistas e fornecedores nos compromissos de compra que são firmados. Na prática, os negociadores de ambos os lados barganham em favorecimento próprio e o resultado depende do 
balanço de forças do canal. Também se deve considerar que os contratos de compra/venda são freqüentemente revisados e cada revisão gera a oportunidade de refinamentos, reconsiderações e continuidade (ou não) da relação comercial (TSAY, 2001). Trata-se, portanto, de um processo complexo, não considerado em sua totalidade no presente estudo. Sugere-se como possibilidades de futuras pesquisas a análise de outros segmentos de mercado, bem como a utilização de outras métricas tais como retorno sobre investimento (ROI) e ou lucratividade em geral.

\section{Referências}

AC Nielsen: índice AC Nielsen de varejo, ano móvel terminado em janeiro de 2010.

AGRAWAL, N.; SMITH, S. A. Optimal retail assortments for substitutable items purchased in sets. Naval Research Logistics, v.50, p. 793-822, 2003.

ARKADER, R.; FERREIRA, C. F. Category management initiatives from the retailer perspective: a study in the Brazilian grocery retail industry. Journal of Purchasing and Supply Management, v. 10, n. 1, p. 41-51, 2004.

BERTAGLIA, P. R. Logística e gerenciamento da cadeia de abastecimento. 2. ed. rev. atual. São Paulo: Saraiva, 2009.

BLAYNEY, D. P.; GEHLHAR, M .J. U.S. dairy at a new crossroads in a global setting. Amber Waves, USA, v. 3, n. 5, p. 32-37, 2005.

BOATWRIGHT, P.; NUNES, J. C. Reducing assortment: an attribute-based approach. Journal of Marketing, v. 65, n. 3, p. 50-63, 2001.

BOWERSOX, D. J.; CLOSS, D. J.; COOPER, M. B. Gestão logística de cadeias de suprimentos. Porto Alegre: Bookman, 2006. 
BOYD, D. E.; BAHN, K. D. When do large product assortments benefit consumers? An information-processing perspective. Journal of Retailing, v.85, n.3, p. 288-297, 2009.

BRONIARCZYK, S. M.; HOYER, W. D.; McALISTER, L. Consumer perceptions of the assortment offered in a grocery category: the impact of item reduction. Journal of Marketing Research, v. 35, p. 166-176, 1998.

CADEAUX, J. M. A closer look at the interface between the product lines of manufacturers and the assortments of retailers. International Journal of Retail \& Distribution Management, v.25, n.6, p. 197-203, 1997.

CAMPO, K.; GIJSBRECHTS, E. Retail assortment, shelf and stockout management: issues, interplay and future challenges. Applied Stochastic Models in Business and Industry, v.21, p. 383-392, 2005.

CAMPOS, L. H. R de; STAMFORD, A.; CAMPOS, M. de F. S de S.; Otimizando a capacidade de crescimento numa cadeia produtiva supermercadista. Revista Produção, v,12, n.1, p. 6-17, 2002.

CAO, W.; JIANG, B.; ZHOU, D. The effects of demand uncertainty on channel structure. European Journal of Operational Research, v. 207, p. 1471-1488, 2010.

CHOPRA, S.; MEINDL, P. Gerenciamento da cadeia de suprimentos: estratégia, planejamento e operações. São Paulo: Pearson Prentice Hall, 2006.

GREWAL, D. et al.. Planning merchandising decisions to account for regional and product assortment differences. Journal of Retailing, v.75, n.3, p. 405-424, 1999. 
HOLMSTRÖM, J. et al.. Collaborative planning forecasting and replenishment: new solutions needed for mass collaboration. Supply Chain Management: An International Journal, v.7, n.3, p. 136-145, 2002.

IYENGAR, S. S.; LEPPER, M. R. When choice is demotivating: can one desire too much of a good thing? Journal of Personality and Social Psychology, v. 79, n. 6, p. 995-1006, 2000 .

KIM, K. On determinants of joint action in industrial distributor-supplier relationships: beyond economic efficiency. International Journal of Research in Marketing, v. 16, p. 217-236, 1999.

KÖK, A. G.; FISHER, M. L.; VAIDYANATHAN, R. Assortment planning: review of literature and industry practice. In: AGRAWAL, N.; SMITH, S. A. Retail Supply Chain Management. Amsterdam: Kluwer, 2006.

LAMBERT, D. M.; COOPER, M. C. Issues in supply chain management. Industrial Marketing Management, v.29, p. 65-83, 2000.

LEE, H. L.; PADMANABHAN, V.; WHANG, S. Information distortion in a supply chain: the bullwhip effect. Management Science, v. 43, n. 4, p. 546-558, 1997.

MANTRALA, M. K. et al.. Why is assortment planning so difficult for retailers? A framework and research agenda. Journal of Retailing, v.85, n.1, p. 71-83, 2009.

McLAREN, T; HEAD, M.; YUAN, Y. Supply chain collaboration alternatives: understanding the expected costs and benefits. Eletronic Networking Applications and Policy, v.12, n.4, p. 348-364, 2002. 
OPPEWAL, H.; KOELEMEIJER, K. More choice is better: effects of assortment size and composition on assortment evaluation. International Journal of Research in Marketing, v. 22, n. 1, p. 45-60, 2005.

RAJARAM, K. Assortment planning in fashion retailing: methodology, application and analysis. European Journal of Operational Research, v. 129, n. 1, p. 186-208, 2001.

SANTOS, A. M.; GIMENEZ, L. C. P. G. Reestruturação do comércio varejista e de supermercados. BNDES Setorial, v. 9, 1999.

TSAY, A. A. Managing retail channel overstock: markdown money and return policies. Journal of Retailing, v. 77, p. 457-492, 2001.

VOSS, C.; TSIKRIKTSIS, N.; FROHLICH, M. Case research in operations management. International Journal of Operations \& Production Management, v. 22, n. 2, p. 195-219, 2002 .

WILKIE, W. L.; DESROCHERS, D. M.; GUNDLACH, G. T. Marketing research and public policy: the case of slotting fees. Journal of Public Policy and Marketing, v.21, n.2, p. 275-288, 2002.

YIN, R. Case study research: design and methods. Beverly Hills: Sage Publications, 1987

YUCEL, E. et al.. Optimizing product assortment under customer-driven demand substitution. European Journal of Operational Research, v. 199, p. 759-768, 2009. 